\title{
Excitation/Detection Strategies for OH Planar Laser- Induced Fluorescence Measurements in the Presence of Interfering Fuel Signal and Absorption Effects
}

Christopher M. Heath, Robert C. Anderson, and Yolanda R. Hicks

Glenn Research Center, Cleveland, Ohio

Randy J. Locke

ASRC Aerospace, Inc., Cleveland, Ohio 


\section{NASA STI Program . . . in Profile}

Since its founding, NASA has been dedicated to the advancement of aeronautics and space science. The NASA Scientific and Technical Information (STI) program plays a key part in helping NASA maintain this important role.

The NASA STI Program operates under the auspices of the Agency Chief Information Officer. It collects, organizes, provides for archiving, and disseminates NASA's STI. The NASA STI program provides access to the NASA Aeronautics and Space Database and its public interface, the NASA Technical Reports Server, thus providing one of the largest collections of aeronautical and space science STI in the world. Results are published in both non-NASA channels and by NASA in the NASA STI Report Series, which includes the following report types:

- TECHNICAL PUBLICATION. Reports of completed research or a major significant phase of research that present the results of NASA programs and include extensive data or theoretical analysis. Includes compilations of significant scientific and technical data and information deemed to be of continuing reference value. NASA counterpart of peer-reviewed formal professional papers but has less stringent limitations on manuscript length and extent of graphic presentations.

- TECHNICAL MEMORANDUM. Scientific and technical findings that are preliminary or of specialized interest, e.g., quick release reports, working papers, and bibliographies that contain minimal annotation. Does not contain extensive analysis.

- CONTRACTOR REPORT. Scientific and technical findings by NASA-sponsored contractors and grantees.
- CONFERENCE PUBLICATION. Collected papers from scientific and technical conferences, symposia, seminars, or other meetings sponsored or cosponsored by NASA.

- SPECIAL PUBLICATION. Scientific, technical, or historical information from NASA programs, projects, and missions, often concerned with subjects having substantial public interest.

- TECHNICAL TRANSLATION. Englishlanguage translations of foreign scientific and technical material pertinent to NASA's mission.

Specialized services also include creating custom thesauri, building customized databases, organizing and publishing research results.

For more information about the NASA STI program, see the following:

- Access the NASA STI program home page at http://www.sti.nasa.gov

- E-mail your question via the Internet to help@ sti.nasa.gov

- Fax your question to the NASA STI Help Desk at $443-757-5803$

- Telephone the NASA STI Help Desk at 443-757-5802

- Write to: NASA Center for AeroSpace Information (CASI) 7115 Standard Drive Hanover, MD 21076-1320 


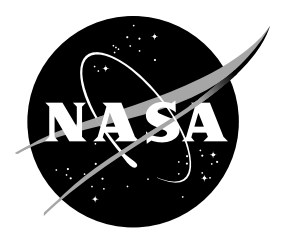

\section{Excitation/Detection Strategies for OH Planar Laser- Induced Fluorescence Measurements in the Presence of Interfering Fuel Signal and Absorption Effects}

Christopher M. Heath, Robert C. Anderson, and Yolanda R. Hicks

Glenn Research Center, Cleveland, Ohio

Randy J. Locke

ASRC Aerospace, Inc., Cleveland, Ohio

Prepared for the

46th Joint Propulsion Conference and Exhibit

cosponsored by the AIAA, ASME, SAE, and ASEE

Nashville, Tennessee, July 25-28, 2010

National Aeronautics and

Space Administration

Glenn Research Center

Cleveland, Ohio 44135 
This report contains preliminary findings, subject to revision as analysis proceeds.

Trade names and trademarks are used in this report for identification only. Their usage does not constitute an official endorsement, either expressed or implied, by the National Aeronautics and Space Administration.

This work was sponsored by the Fundamental Aeronautics Program at the NASA Glenn Research Center.

Level of Review: This material has been technically reviewed by technical management.

Available from

NASA Center for Aerospace Information 7115 Standard Drive

Hanover, MD 21076-1320
National Technical Information Service 5301 Shawnee Road Alexandria, VA 22312

Available electronically at http://gltrs.grc.nasa.gov 


\title{
Excitation/Detection Strategies for OH Planar Laser-Induced Fluorescence Measurements in the Presence of Interfering Fuel Signal and Absorption Effects
}

\author{
Christopher M. Heath, Robert C. Anderson, and Yolanda R. Hicks \\ National Aeronautics and Space Administration \\ Glenn Research Center \\ Cleveland, Ohio 44135 \\ Randy J. Locke \\ ASRC Aerospace, Inc. \\ Cleveland, Ohio 44135
}

\begin{abstract}
Planar laser-induced fluorescence (PLIF) excitation/detection methods have been applied to obtain spatial distributions of the hydroxyl $[\mathrm{OH}]$ reacting intermediary and hydrocarbon $[\mathrm{HC}]$ primary species in laminar and turbulent combustion reactions. In this report, broadband and narrowband excitation/filtering techniques are explored to identify an optimal experimental configuration yielding significant fluorescent signal with low absorption losses. The combustion environments analyzed include 1) a laminar nonpremixed methane/air flame and 2) a turbulent, non-premixed Jet-A/air fueled flame within a lean flame tube combustor. Hydrocarbon-based fuel and $\mathrm{OH}$ were excited via the $R_{1}(1), R_{1}(10)$ and $R_{2}(7)$ transitions of the $A^{2} \Sigma^{+} \leftarrow X^{2} \Pi(1,0)$ band using a broadband Nd:YAG pumped optical parametric oscillator (OPO) and narrowband $\mathrm{Nd}$ :YAG/dye laser with ultraviolet frequency extension (UVX) package. Variables tested for influence on fluorescent signal and absorption characteristics were excitation line, laser energy, exciting linewidth, combustion reactants, and test flow conditions. Results are intended to guide the transition from a dye/UVX laser to an OPO system for performing advanced diagnostics of low-emission combustion concepts.
\end{abstract}

\section{Nomenclature}

$\begin{array}{ll}\text { AR } & \text { anti-reflective } \\ \text { FWHM } & \text { full-width at half maximum } \\ \text { HTHP } & \text { high temperature, high pressure } \\ \text { ICCD } & \text { intensified, charge-coupled device } \\ \text { LDI } & \text { lean direct injection } \\ \text { LSF } & \text { laser saturated fluorescence } \\ \text { NCC } & \text { national combustion code } \\ \text { Nd:YAG } & \text { neodymium: yttrium aluminum garnet } \\ \text { NO } & \text { oxides of nitrogen } \\ \text { OH } & \text { hydroxyl radical } \\ \text { OPO } & \text { optical parametric oscillator } \\ \text { PAH } & \text { polycyclic aromatic hydrocarbons } \\ \text { PLIF } & \text { planar laser-induced fluorescence } \\ \text { UHC } & \text { unburned hydrocarbon } \\ \text { UV } & \text { ultraviolet } \\ \text { UVX } & \text { ultraviolet frequency extension }\end{array}$




\subsection{Introduction}

Emission regulations for the next-generation of air-based propulsion systems call for the development and evaluation of advanced initiatives in low- $\mathrm{NO}_{\mathrm{x}}$ combustion research. Candidate emission reduction technologies, including advanced fuel injection hardware and alternative fuels, are often validated using non-intrusive and in-situ measurement techniques (namely, remote laser diagnostics conducted in a combustion chamber with optical access). Unfortunately, these types of flow interrogation methods often suffer from optical complications that must be characterized and, if possible, corrected. Countering such complexities requires a thorough investigation of interfering factors, including the development of error mitigation techniques and corrective procedures to improve the quality of experimentally acquired data.

Planar laser-induced fluorescence (PLIF) is an optical imaging process for obtaining spatially and temporally resolved two-dimensional chemical species, temperature, pressure and velocity measurements (Ref. 1). In standard PLIF, a targeted molecular species is excited from a ground-level electronic state of specific rotational and vibrational energy to a higher electronic state via photon absorption of incident laser radiation. Various decay processes, including fluorescence, provide a means for the laser-excited molecules to revert to a stable energy level. Emitted fluorescence from this process is captured and related to the number density of the excited molecular species. PLIF has been reported in many studies as an effective means to describe flame location, flow structure, regions of recirculation and chemical composition in reacting flows (Refs. 1 to 5). The technique is most conventionally used to image concentration of minor and intermediate combustion species including $\mathrm{CH}, \mathrm{OH}, \mathrm{NO}$ and certain unburned hydrocarbons (UHCs). Of particular interest to aircraft emission research is imaging of the hydroxyl [OH] and UHC groups, which together may be used to describe fuel patternation, mixing performance and efficiency for a given fuel injection system or combustor architecture. Successful imaging of the $\mathrm{OH}$ radical by means of laser-induced fluorescence under realistic engine operating conditions requires overcoming several adverse effects. Problems include interference from overlapping fuel signal, pressureinduced line broadening and laser attenuation. Techniques to mitigate these complications and produce useful, more quantitative $\mathrm{OH}$ imaging data are the primary focus of this study.

Several characteristics make the $\mathrm{OH}$ radical a valuable species for indirectly gauging combustor system level performance. There exists a large spectroscopic database for $\mathrm{OH}$; there is good separation between its rovibronic lines with limited spectral interference (Ref. 4), and it is more easily and safely resolved than species like $\mathrm{NO}$. $\mathrm{OH}$ is capable of providing insight into the physical flow structure, chemical composition and temperature distribution of reacting flows. In the exothermic hydrocarbon-air reaction, $\mathrm{OH}$ most readily forms at the flame front and its spatial distribution marks locations of heat release. Regions of high temperature increase thermal $\mathrm{NO}_{\mathrm{x}}$ formation and may reduce the lifetime of critical engine components (Ref. 2). The ability to track thermal intensity and sites of non-uniform mixing through the presence of $\mathrm{OH}$ is useful for testing operating methods, evaluating hardware designs and influencing future modifications to reduce emissions and further enhance combustor performance. Species and temperature are also important parameters for validating and improving the fidelity of computational models that simulate the complex, multiphase interactions and turbulent flow structures typically found in the combustion pathways of gas turbine engines.

Historically, OH PLIF has been employed effectively in low and atmospheric pressure flame experiments using gaseous fuel and oxidizer (Ref. 4). Such conditions are atypical of the multiphase and high-pressure environments of aircraft combustion systems. Known complications encountered in performing quantitative PLIF measurements in real combustor settings include laser attenuation attributed to absorption, pressure-induced line broadening, spectral interferences, collisional fluorescent quenching and spectral overlap between species containing similar emission signatures (Refs. 2 and 6). For example, polycyclic aromatic hydrocarbons (PAHs) - common constituents in aviation fuels that include naphthalene and its derivatives - absorb and emit energy over a broad spectrum often competing with the fluorescent emission bands of the $\mathrm{OH}$ molecule (Ref. 2). Spectral interferences may also arise due to elastically scattered light from liquid fuel and, if the flame is luminous, blackbody radiation (Ref. 4). To reduce the influence of such phenomena, a variety of $\mathrm{OH}$ excitation lines have been tested with laminar 
and turbulent reacting flows to identify a least absorbing transition that produces optimal $\mathrm{OH}$ fluorescent signal. Additionally, narrowband and wideband spectral filters have been applied in each transition case to identify an excitation/detection combination that most effectively isolates spectral emissions of the $\mathrm{OH}$ radical from other constituents.

A variety of investigations (Refs. 2 to 4 , and 6 to 8 ) report the use of PLIF and spectroscopic techniques to study flame structure, composition and absorption effects in atmospheric as well as high temperature and high pressure combustion environments. Much of the laboratory work has been aimed at refining methods to produce quantitative species and local temperature measurements for use in practical combustion applications. Common areas of research to enhance measurement integrity include excitation/detection strategies, laser energy/attenuation corrections and background subtraction methods for increasing signal-to-noise ratios.

Seitzman et al. (Ref. 3) assessed a variety of techniques for exciting $\mathrm{OH}$ with the objective of identifying a method for minimizing combined systematic and random experimental errors. Solution of a time-dependent rate model for population densities demonstrated that dye laser excitation of the $A^{2} \Sigma^{+} \leftarrow X^{2} \Pi(1,0)$ band produced high signals with low overall error, ideal for quantitative single-shot imaging of hydrocarbon-air flames.

Hicks et al. (Refs. 2 and 4) used PLIF for flame structure visualization in an optically accessible Jet-A fueled lean flame tube combustor to simulate a working gas turbine engine environment. Excitation of $\mathrm{OH}, \mathrm{NO}$ and fuel was performed while also exploring the effects of narrow and broadband filtering techniques to remove unwanted interfering spectra. Operating conditions were varied to simulate realistic flight conditions with overall equivalence ratios near 0.5 . Frame averaging was applied to provide qualitative flow field characteristics, flame structure and fuel patternation information. Complexities noted in obtaining quantitative results included spectral interferences, turbulence interactions and highpressure effects such as spectral line broadening. Using a narrow passband filter centered on a region more isolated from the fuel fluorescent emission signature was suggested to reduce elastic scattering and interference. Real time laser energy absorption measurements were also recommended for future quantitative measurements. The need for an independent parametric study was mentioned to gain a better understanding of fluorescent temperature and pressure dependence.

Cooper et al. (Ref. 6) performed quantitative laser-saturated fluorescence (LSF) measurements of nitric oxide (NO) in a turbulent spray flame produced by a heptane fueled lean direct injector (LDI) at atmospheric pressure. The flame was operated at an equivalence ratio of unity in order to influence the NO formation mechanism. NO was excited via the $Q_{2}(26.5)$ transition of the $\gamma(0,0)$ band at $225.58-\mathrm{nm}$ and observed at the $\gamma(0,1)$ band using a 2-nm wide detection window centered at 235.58-nm. Preliminary excitation and detection scans were conducted using a $\mathrm{C}_{2} \mathrm{H}_{6} / \mathrm{O}_{2} / \mathrm{N}_{2}$ flame doped with $80 \mathrm{ppm} \mathrm{NO}$ to reveal a lack of fluorescent interference from UHCs and PAHs within the narrow detection range. An off-line background subtraction method was applied to remove elastic scattering effects and isolate NO concentration.

Cavity-ring down spectroscopy has been reported by Lozovsky et al. (Ref. 7) to obtain absolute temperature and concentration profiles of $\mathrm{OH}$ in methane/air flames. The work focused on the analysis of methane/nitrogen/oxygen flames (with nitrogen shroud gas) at low pressures ( $\sim 30$ torr). Flames with equivalence ratios of $0.8,1.0$ and 1.2 were studied and compared with combustion models demonstrating discrepancy between experimental and predicted results. This disagreement suggested the need for future analysis and model refinement.

In 2005, Baranger et al. (Ref. 8) reported experiments using spectroscopy to measure the influence of temperature, pressure and mixture composition on the fluorescence of kerosene vapor contained in a high temperature and pressure cell. The optically accessible vessel was operated between 400 and $700 \mathrm{~K}$, at pressures between 0.1- and 0.7-MPa. Fluorescent spectra were acquired for excitation wavelengths of 266-, 282- and 308-nm demonstrating a double fluorescent band structure that was attributed to the presence of several pure single and two-ring aromatics. A major loss in fluorescent signal was noted for the 282- and 308-nm excitation wavelengths and attributed to the broadband absorption properties of fuel constituents. Increasing temperature exhibited a decrease in kerosene fluorescence with spectral distortion 
noted at the upper wavelengths of the spectra. Fluorescent signal was found to decrease linearly across the entire spectrum with a respective increase in pressure. Collision quenching by $\mathrm{O}_{2}$ measurements indicated a near-linear relationship between fluorescent intensity and the experimental oxygen molar fraction. The findings were used to perform quantitative fluorescent imaging of local equivalence ratio and temperature on a preheated kerosene/air jet exiting in ambient air.

The following text describes and compares results from PLIF measurements made during combustion testing at both atmospheric and high-pressure conditions. Test venues included a Hencken burner and a flame tube combustor. Laser configurations included a Nd:YAG/dye pumped UVX system and a $\mathrm{Nd}$ :YAG pumped OPO. Optical configuration variations included use of a narrowband and wideband filter on the detector. Other parameters varied during these tests included fuel flow rate and, in the case of the flame tube facility, inlet pressure and temperature. Data from all testing has been processed similarly. Specifically, processing of all images has included off-line background subtraction, frame averaging and noise removal. PLIF measurements of $\mathrm{OH}$ are the focus of this study with the objective of optimizing laser and optical configurations for future experiments.

\subsection{Experimental Hardware}

\subsection{Laser Systems}

PLIF imaging was performed using 1) a Continuum Nd:YAG (NY-81C) laser set to pump a tunable dye system (ND6000) employing Rhodamine 590 (R-590) dye with output frequency doubled by means of an ultraviolet frequency extension (UVX) package and 2) a Continuum Nd:YAG (9010) pumped Optical Parametric Oscillator (OPO).

For the dye laser configuration, the Nd:YAG was frequency doubled (532-nm) and the second harmonics produced $\sim 750-\mathrm{mJ} /$ pulse at a repetition rate of $10-\mathrm{Hz}$. The dye laser operated with an energy/pulse of $\sim 180-\mathrm{mJ}$ at $564-\mathrm{nm}$. Using a frequency doubler/mixer (UVX) in a UVT-1 configuration, output from the dye laser was frequency doubled to produce the desired wavelength near 282-nm with output linewidth near $0.05-\mathrm{cm}^{-1}$. Pulsed dye laser drift was monitored and controlled using a dye tracking system. UV light was separated from the fundamental output wavelength using a Pellin-Broca prism mounted at the exit of the UVX. The 282-nm laser output energy was maintained near $\sim 16-\mathrm{mJ} / \mathrm{pulse}$.

For the OPO system, the fundamental wavelength of the pumping $\mathrm{Nd}$ :YAG was frequency tripled (355-nm), producing a third harmonic at $300-\mathrm{mJ} /$ pulse with a repetition rate of $10-\mathrm{Hz}$. The OPO linewidth specification is less than $6-\mathrm{cm}^{-1}$ and the output energy was maintained near $6-\mathrm{mJ} / \mathrm{pulse}$.

The two laser systems were tuned to excite one of three specific rovibronic transitions of the $\mathrm{OH}$ $A \leftarrow X(1,0)$ band: $R_{1}(1), R_{1}(10)$ and $R_{2}(7)$. The accepted wavelengths corresponding to each transition line can be found in Ref. 9. Figure 1 shows fluorescence excitation scans about these lines. The OPO was scanned at a rate twice that of the dye/UVX and covers a larger range of wavelengths to access the low absorption (off-line) region in front of the $\mathrm{OH} A \leftarrow X(1,0)$ band head. The off-line wavelength for the dye/UVX laser was between the $R_{1}(1)$ and $R_{1}(10)$ excitation lines. Previous research has indicated that this excitation and detection scheme has helped to reduce fluorescent trapping, absorption of the emitted $\mathrm{OH}$ fluorescence by other $\mathrm{OH}$ molecules and elastic laser scattering effects (Refs. 3, 5, and 10). Resonant and off-resonant excitations were confirmed by observing the level of $\mathrm{OH}$ fluorescence emitted from a laminar methane/air Bunsen burner flame using a photomultipler tube/boxcar average system.

One of the goals of this research is to measure and compare the capabilities of the dye/UVX and OPO lasers, with the intention of using the OPO system exclusively in future laser diagnostic experiments. Several factors make the OPO laser more attractive than the dye/UVX system including: all solid-state; environmentally benign materials (no toxic chemicals are required for operation); reduced size and footprint compared to dye/UVX configuration; broad tuning range (from 205- to 2250-nm) without requiring a change of dye; and higher power at $\sim 225-\mathrm{nm}$ for NO fluorescence. The dye-UVX combination does, on the other hand, produce greater power output at a narrower linewidth near the $\mathrm{OH}$ excitation wavelengths, which is evidenced by the high quality UVX PLIF images contained later in this report. 


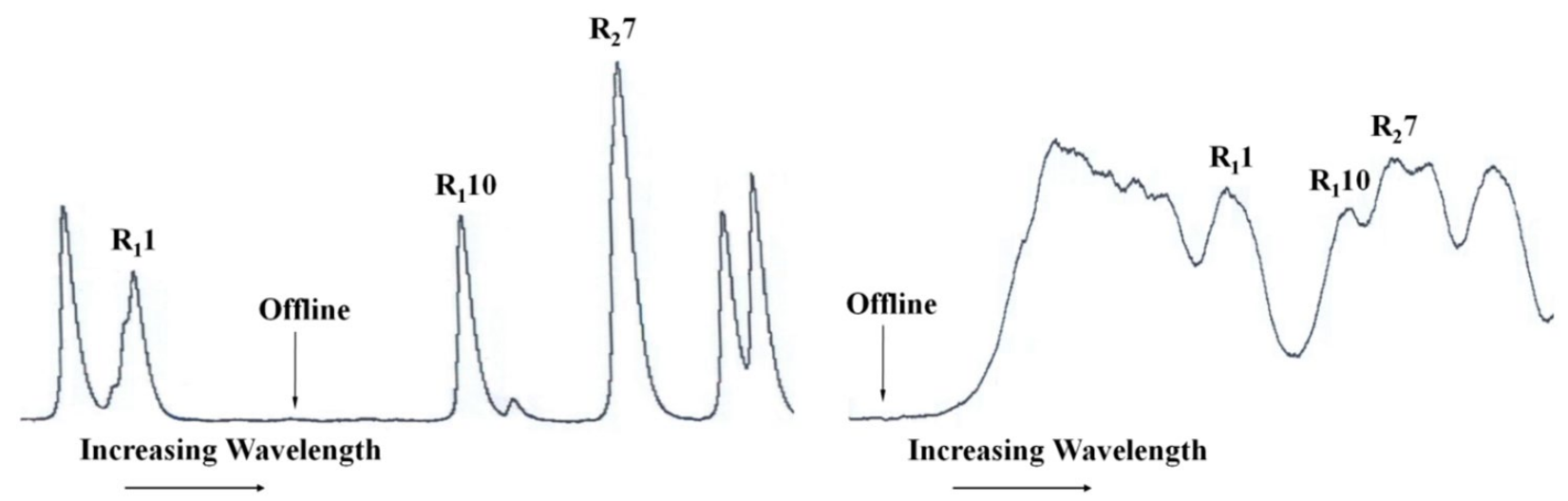

Figure 1.- $\mathrm{OH}$ excitation scans for UVX (left) and OPO (right) identifying the $R_{1}(1), R_{1}(10)$ and $R_{2}(7)$ rovibronic transitions.

\subsection{Detector Systems}

The detector used in these experiments was a 16-bit Princeton Instruments gated and intensified charge coupled device (ICCD) camera with detector array of $1024 \times 1024$ pixels. A Princeton Instruments programmable timing generator was used to synchronize the camera intensifier with the fluorescence induced by the laser pulse. The detectors were gated for 50-ns exposures using Princeton Instruments ST133 control units.

$\mathrm{OH}$ fluorescence from the $(1,1)$ band near $315-\mathrm{nm}$ was collected using an $\mathrm{f} / 4.5, \mathrm{f}=105-\mathrm{mm} \mathrm{UV}$ grade lens. To achieve spectral isolation, either a 315-nm center wavelength, $\sim 3.4-\mathrm{nm}$ full-width at half maximum (FWHM) (narrow passband) filter with peak transmittance of $\sim 16.1$ percent, or a 314.4-nm centered, $\sim 11.8$-nm FWHM (wide passband) filter with peak transmittance near 16.8 percent were applied. Previous experiments have indicated that unwanted or excessive fluorescence from fuel may be permitted to pass to the detector with exclusive use of a wide (>10-nm FWHM) passband filter. Although the effects of signal from fuel can be reduced using background subtraction, further restriction by applying a filter with narrower passband aids in minimizing noise from fuel fluorescence.

\subsection{Image Processing and Analysis}

For each planar $\mathrm{OH}$ measurement, both on-line and off-line images were taken. Image processing software was used to subtract the off-line or background image. Image pixel values were scaled from 0 to 255 for displays using a 256-color palette. Anomalous pixels were removed and reset to the average intensity value of the directly surrounding region using a software routine developed to detect and reduce image noise spikes. The source of unusually high intensity pixels is unknown, but particle emissions, signal noise, detector chip defects and scattered laser radiation onto the detector are all potential causes (Ref. 2). All images were rebinned to $512 \times 512$ pixels. Intensity profiles were extracted and used for calculating average photon absorption through the flame. Because the output power of the UVX and OPO laser systems varied significantly (by a factor near three), images were scaled separately for each laser and only general trends between the two sets of images are comparable. The full process is represented diagrammatically for a single OH PLIF image in Figure 2. Similar methods were used to process all PLIF images contained herein. 


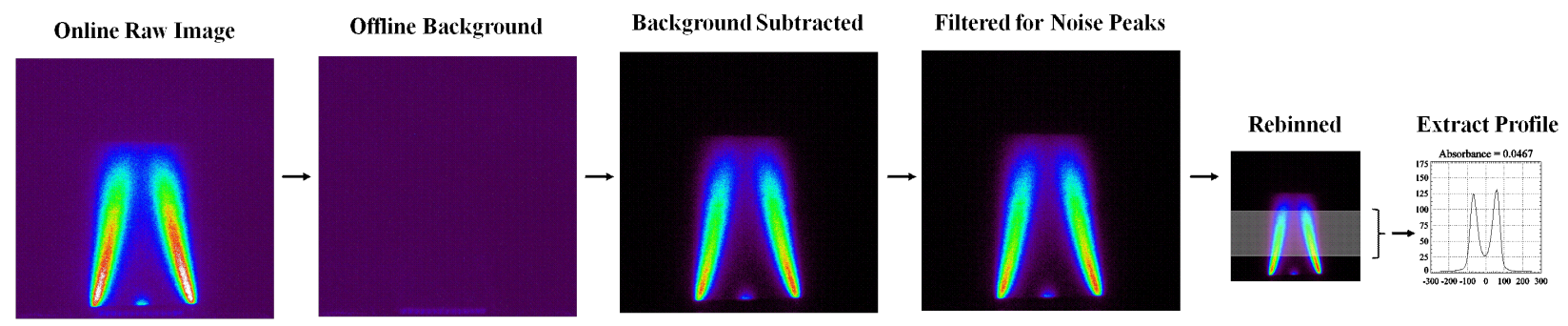

Figure 2.-Diagrammatic image processing description for methane/air fueled Hencken burner experiments.

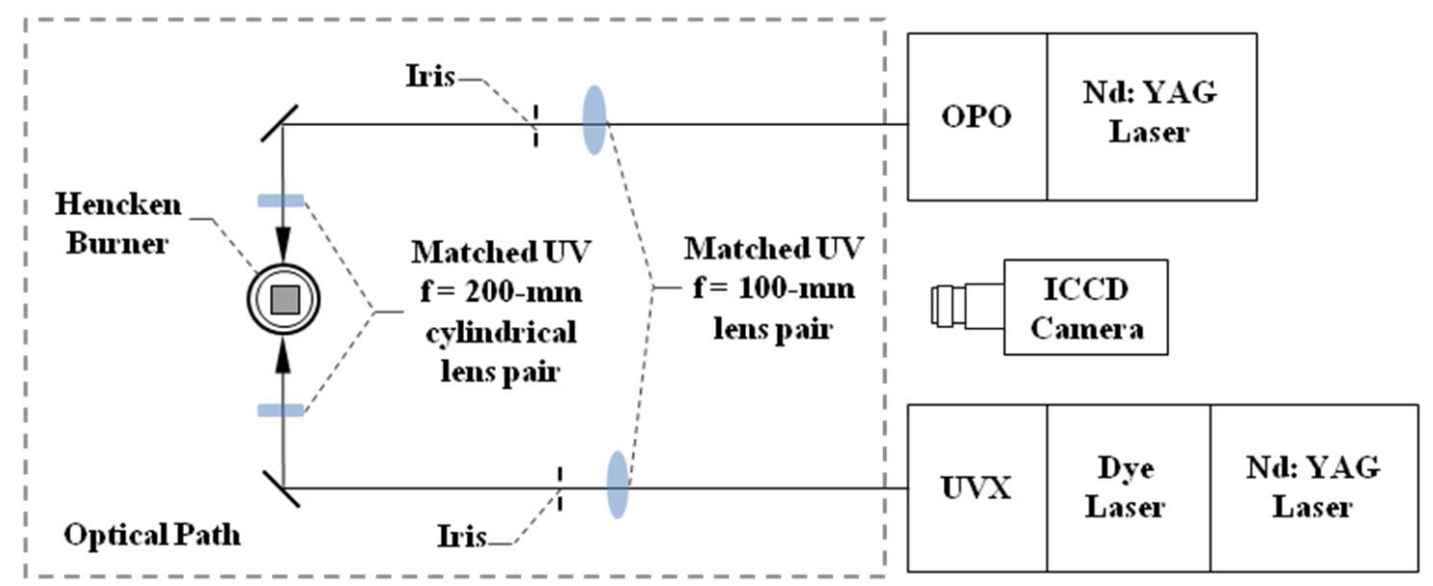

Figure 3.-Optical setup for OH PLIF using a methane/air fueled Hencken burner at atmospheric pressure.

\subsection{Methane/Air Flame Experiments}

OH PLIF measurements were acquired using a non-premixed methane/air flame produced by a Hencken burner (30-mm square multi-element flow path) at atmospheric pressure to obtain qualitative distributions of the reacting $\mathrm{OH}$ intermediary. A Hencken burner consists of a square matrix of capillary tubes that alternately carry fuel or oxidizer. The device produces a two-dimensional flat diffusion flame. All images were acquired by averaging 10 frames, each consisting of on-chip accumulations of 100 gates (laser pulses). The reactant flow rates were regulated using a pair of digital mass flow control units. Fluorescent intensity and absorbance were derived from the PLIF images at the equivalence ratios listed in Table 1. The total volumetric flow rate was kept constant for each flame at 6-SLM.

TABLE 1.-FLAME PARAMETERS \& VOLUMETRIC FLOW RATES (SLM)

\begin{tabular}{|l|c|c|c|c|c|c|}
\hline Reactant gas & $\Phi=0.75$ & $\Phi=1.00$ & $\Phi=1.25$ & $\Phi=1.50$ & $\Phi=1.75$ & $\Phi=2.00$ \\
\hline $\mathrm{CH}_{4}$ & 0.44 & 0.57 & 0.69 & 0.81 & 0.94 & 1.04 \\
Air & 5.56 & 5.43 & 5.31 & 5.19 & 5.06 & 4.96 \\
\hline
\end{tabular}

The setup for the Hencken burner experiment is displayed in Figure 3. OPO and dye/UVX laser optics were matched and collinear overlap was ensured. Each beam was transformed into an optical sheet by transmission through a $200-\mathrm{mm}$ cylindrical lens. The UVX planar beam measured $\sim 30-\mathrm{mm}$ in height by $\sim 0.3-\mathrm{mm}$ in thickness while the OPO beam measured $\sim 50-\mathrm{mm}$ in height by $\sim 0.3-\mathrm{mm}$ in thickness. All lenses were AR coated for 283-nm. The lasers were not operated simultaneously and the in-use input beam was blocked on the far side of the flame to ensure it did not enter the optics of the opposing laser. 
Figures 4 and 5 display the matrix of $\mathrm{OH}$ PLIF images acquired over the full range of equivalence ratios. High $\mathrm{OH}$ signal has been false colored as red. Each set of sixty-four images is scaled collectively for each laser to aid comparison by excitation line and filter. In each case, the flame centerline has been marked by a vertical white line. The laser sheet height for the dye/UVX is slightly greater than for the OPO. The two sets were acquired on two consecutive days. Some variation in flame structure exists between the two sets of images at each fuel/air ratio and may be attributed to imperfect flow rates and outside (ambient) air disturbances. Despite these variations, the images from the two laser systems reveal the same flame structure for a given equivalence ratio.

\section{OH PLIF Images From Hencken Burner Using OPO Laser Configuration}

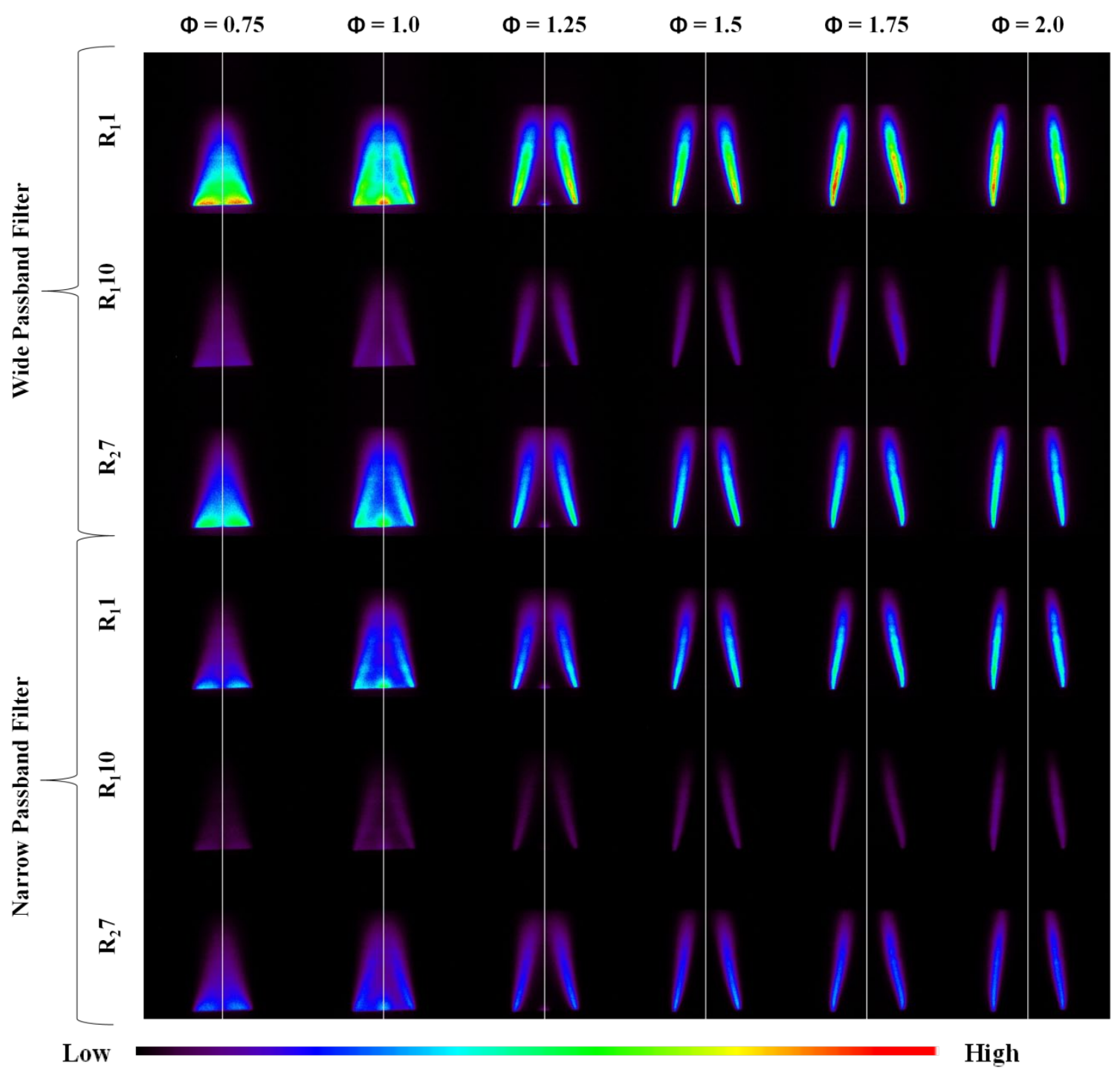

Figure 4.-OH PLIF images from the Hencken burner experiments using the OPO configuration. Images are scaled collectively. A white line denotes approximate flame centerline. Laser beam transmitted right to left. 


\section{OH PLIF Images From Hencken Burner Using UVX Laser Configuration}

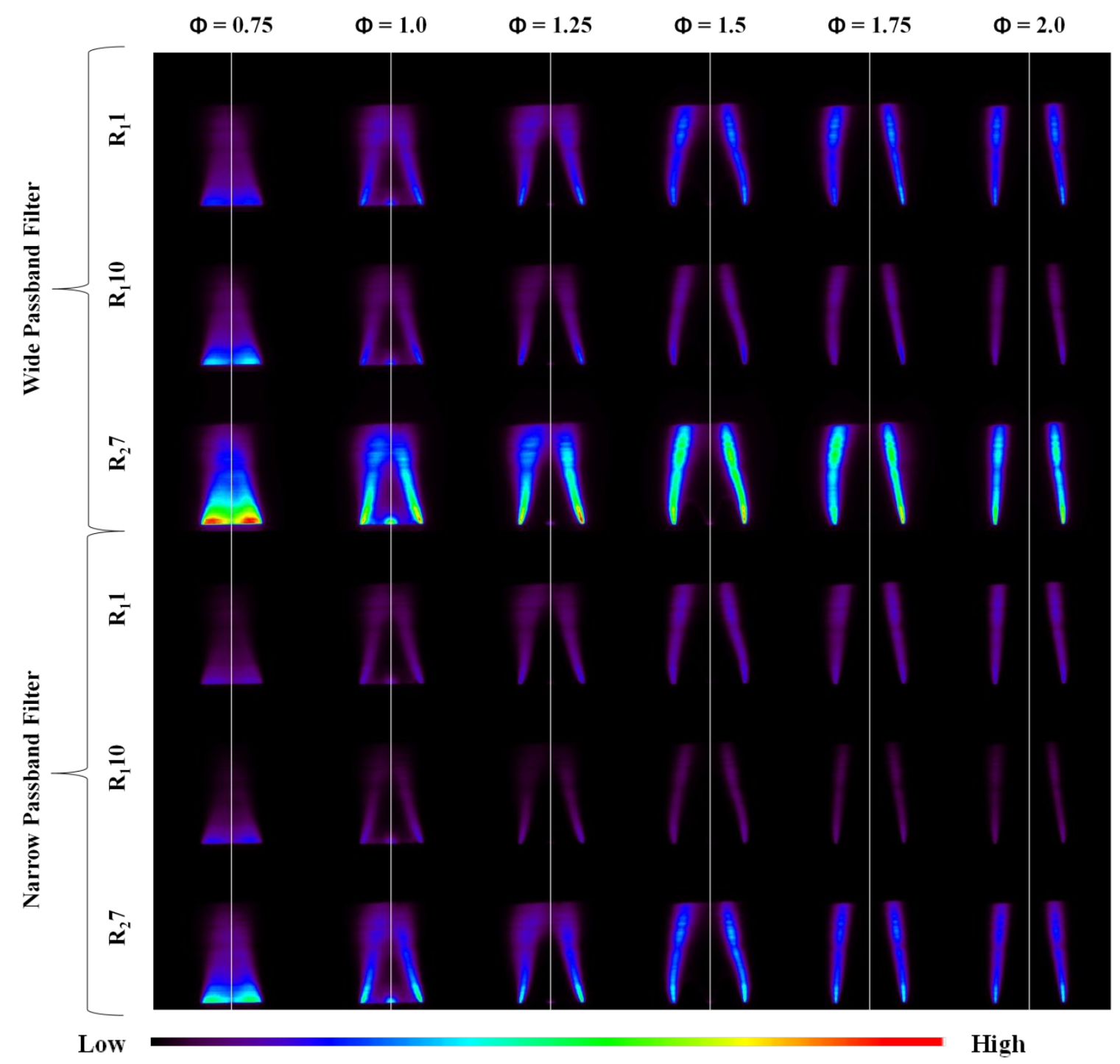

Figure 5.- OH PLIF images from the Hencken burner experiments using the UVX configuration. Images are scaled collectively. A white line denotes approximate flame centerline. Laser beam transmitted left to right.

Qualitative analysis of the methane/air flame OH PLIF images also shows, as expected, lower signal for the narrow passband filter than for the filter with wider passband. Thus, use of a filter with wider detection range will result in greater fluorescent signal but may permit unwanted noise from fuel fluorescence. Another feature that is observable is the non-uniformity of the laser energy distribution, which manifests as horizontal striping in the images. While it occurs for both laser systems, it is particularly evident for the dye/UVX system and somewhat problematic. Improvements in the laser energy profile should result from measuring and correcting for the beam energy profile distribution or from using a more uniform, expanded portion of the beam.

Comparing data from one laser configuration with the other reveals apparent differences in coupling between each laser and the $\mathrm{OH}$ fluorescing species. For the OPO laser, regardless of filter, the $R_{1}(1)$ line appeared to induce the strongest fluorescent signal, followed by the $R_{2}(7)$ and $R_{1}(10)$ lines, in that order. The dye/UVX laser produced differing results as the $R_{2}(7)$ line exhibited the strongest $\mathrm{OH}$ fluorescence 
followed by the $R_{1}(1)$ and $R_{1}(10)$ lines. These results indicate that the $R_{1}(10) \mathrm{OH}$ excitation line provided the weakest fluorescent yield for both laser systems and either filter. Continued efforts used only the $R_{1}(1)$ and $R_{2}(7)$ transition lines.

For the dye/UVX laser, comparison of the resonant and off-resonant images suggests that average offresonant signal comprises less than 5 percent of the on-resonant signal, indicating the relative signal to non-signal ratio is on the order of 19. Average background ranges for the OPO are much higher, comprising 25 to 75 percent of the on-line signal intensity and indicating a significantly lower signal to background ratio than that reported for the dye/UVX system. Although the signal/noise ratio for the OPO laser is comparatively low resulting from low fluorescence levels, the system still provides sufficient detail of $\mathrm{OH}$ location and flame structure for the atmospheric methane-air flame.

A region 225 pixels in height (shown in Fig. 6) was used to obtain the intensity profiles representing the general fluorescent characteristics of each flame. The region was averaged by column to obtain the profiles, which plot the average signal against the distance in pixels from the burner centerline (represented by the 0 location on the horizontal axis). The results from this analysis are displayed in Figures 7 and 8 . The intensity profiles were used to aid in determining average flame structure as they reveal a level of asymmetry that is less apparent by visual examination of the OH PLIF images alone.

To obtain a sense of which excitation lines are least absorbing in a flame environment where no absorption by fuel or PAH molecules is expected, the profiles were used to derive an absorption estimate. (A thorough absorption analysis will be conducted to consider absorption by the PAH in jet fuel as a function of temperature and pressure at a later date.) The areas on either side of the centerline were computed by numerical integration to generate average input-side and output-side fluorescence values. Approximate absorbance for each laser, flame, filter and flow rate combination have been calculated using Equation (1) where $I$ corresponds to the average output-side fluorescence and $I_{0}$ represents the average fluorescence on the beam input-side.

$$
\text { Absorbance }=-\ln \left(\frac{I}{I_{0}}\right)
$$

The approach for calculating absorbance is used only for the purpose of general analysis and should be considered approximate. The $\mathrm{OH}$ distribution is assumed to be symmetric about the flame centerline so that differences in output signal may be solely attributed to absorption. Although the Hencken burner is considered to produce a well-characterized, stable, and symmetric flame, there may be images in which the flame appears non-symmetric. This asymmetry may be due to flow irregularities within the burner itself, or to outside (ambient) air flows interfering with the unshrouded flame. The estimated absorbance values are displayed above each profile. Occasionally, the calculated absorbances reported are negative, indicating higher $\mathrm{OH}$ signal on the laser output side of the flame. In these cases, flame asymmetry is also apparent with higher $\mathrm{OH}$ formation on the output side. (See for instance the OPO wide passband image for line $R_{2}(7)$ at $\phi=1$.)

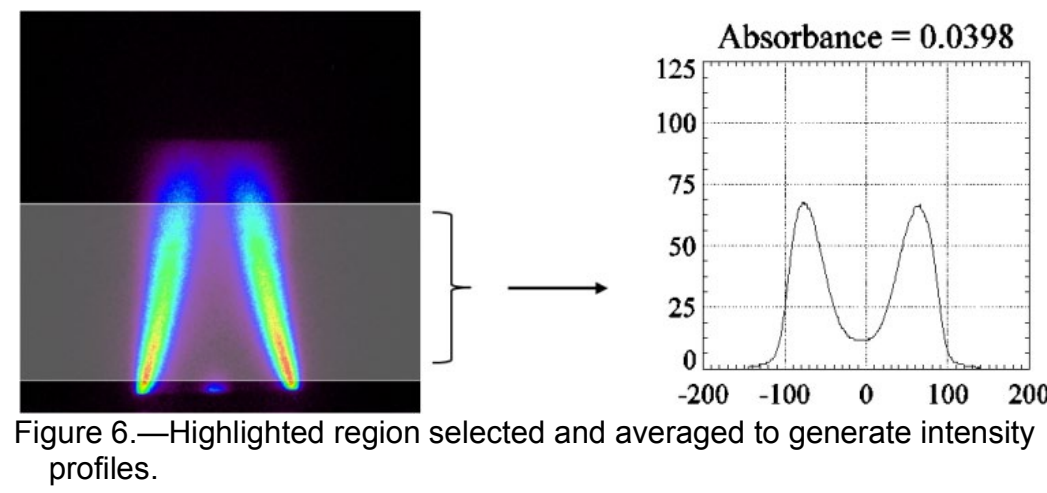


The dye/UVX results were generally consistent across all equivalence ratios and between filters. $R_{1}(10)$ is the least absorbing excitation line on average, (but also produced lowest fluorescence yield) followed by $R_{2}(7)$ and $R_{1}(1)$. In most cases, $R_{2}(7)$ is less absorbing than $R_{1}(1)$ by roughly 40 percent while also providing the highest fluorescent signal, thus making $R_{2}(7)$ the best excitation line in this portion of the study.

The OPO results are much less conclusive, most likely due to the low signal/background levels. Only the narrow passband filter produced fairly consistent results that distinguished the $R_{1}(10)$ line as least absorptive, though with the same caveats as for the dye laser system. The $R_{2}(7)$ and $R_{1}(1)$ lines appear comparable.

\section{Intensity Profiles From Hencken Burner Using OPO Laser Configuration}

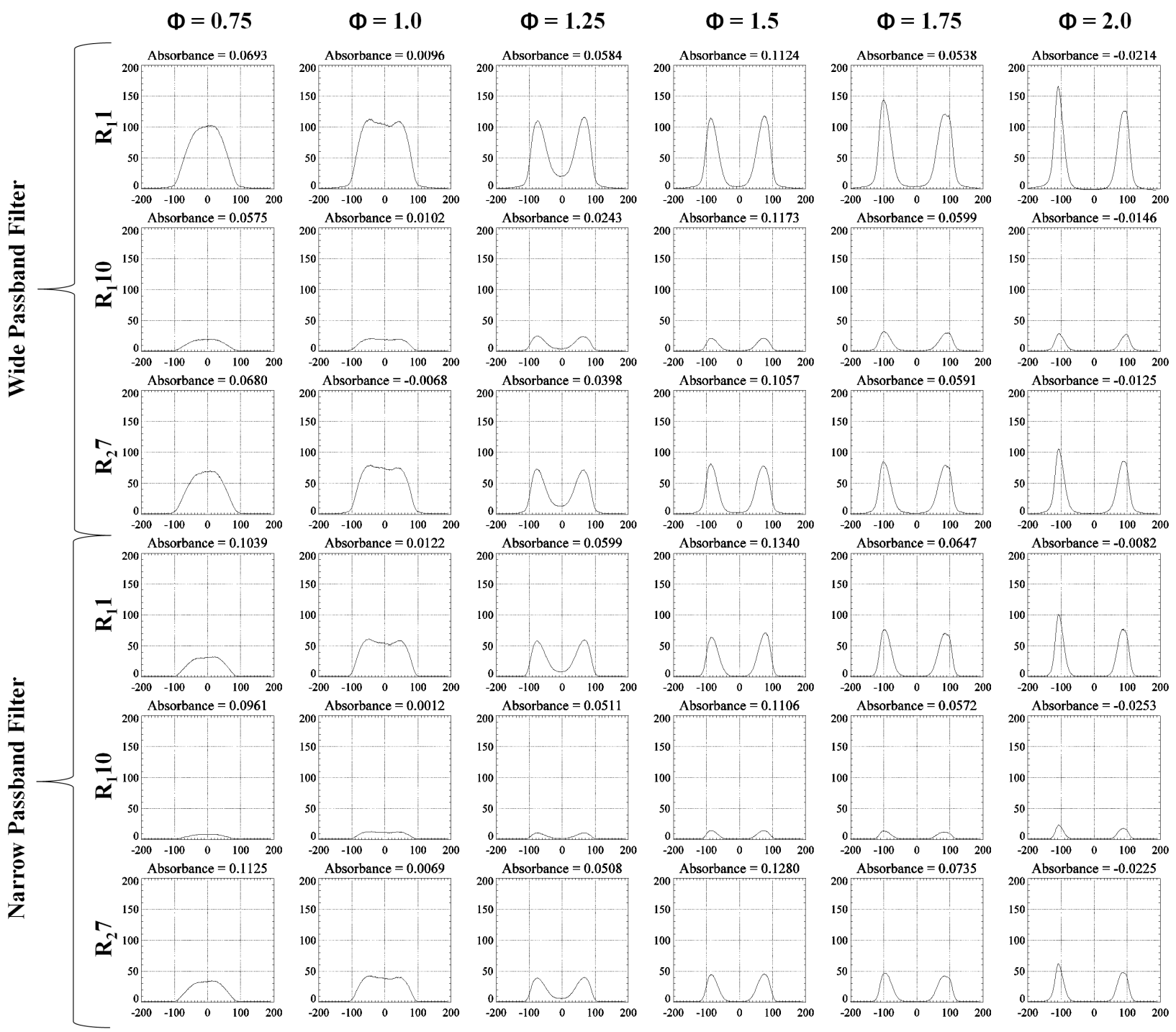

Figure 7.-Average $\mathrm{OH}$ intensity profiles scaled collectively for OPO laser system. (X-axis: Distance in pixels to flame centerline, Y-axis: Average intensity). Laser beam transmitted right to left. 


\section{Intensity Profiles From Hencken Burner Using UVX Laser Configuration}

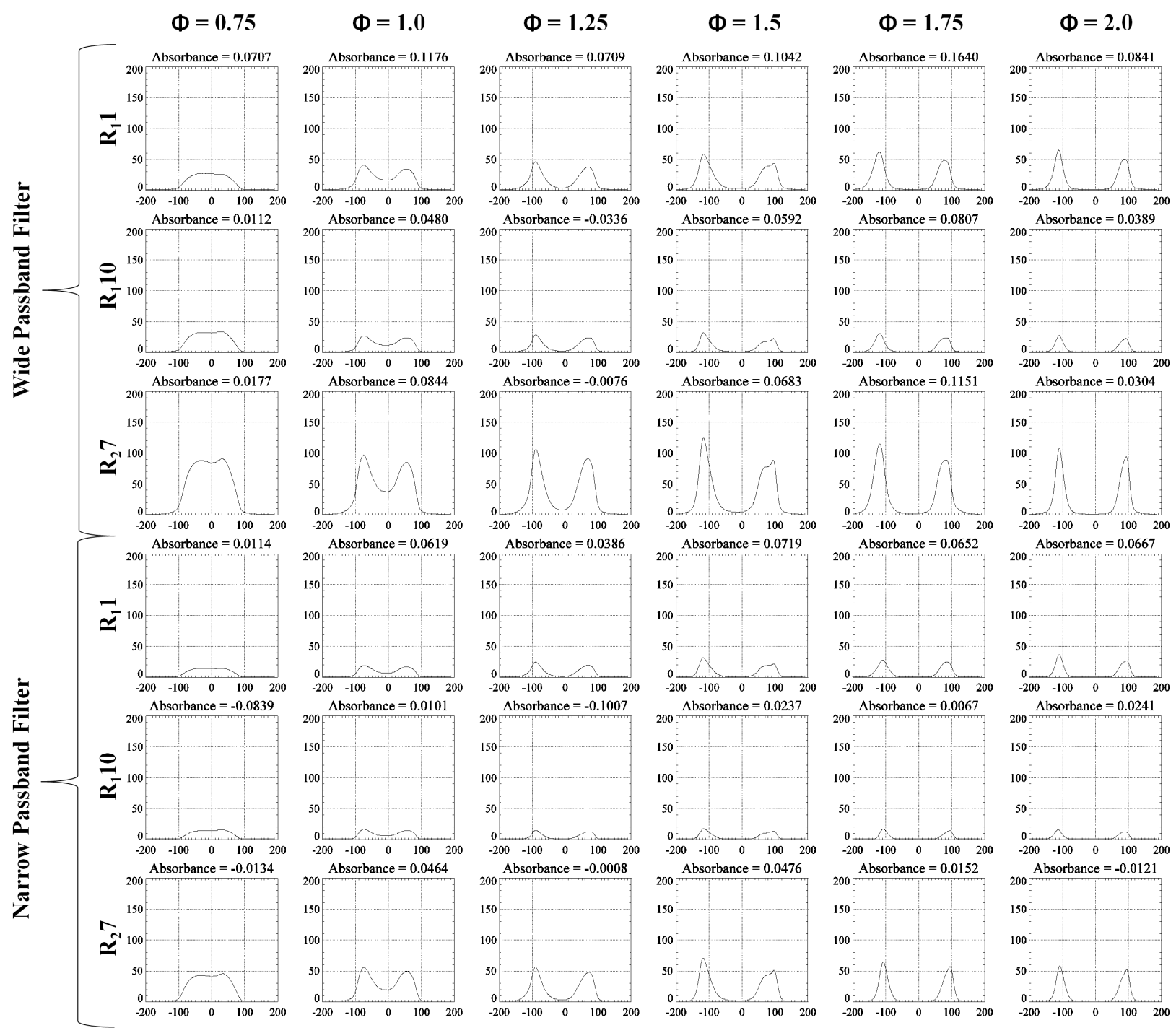

Figure 8.-Average $\mathrm{OH}$ intensity profiles scaled collectively for UVX laser system. (X-axis: Distance in pixels to flame centerline, Y-axis: Average intensity). Laser beam transmitted left to right.

\subsection{Power Survey}

In addition to the matrix of excitation/detection schemes, the effect of laser energy on flame imaging was studied for the dye/UVX system using the $R_{2}(7)$ excitation line and the filter with narrow passband. Results for the 1.25 equivalence ratio flames are displayed in Figure 9. While all power settings resulted in OH PLIF images, the lowest power levels do not provide detail of the local OH distribution within the flame. Rather, as with the low output power OPO laser (6-mW average power), the images demonstrate only the existence of $\mathrm{OH}$ and a flame zone. As might be expected, the average induced $\mathrm{OH}$ fluorescence scales linearly with laser power. (See Fig. 10). Saturation is not evident for the laser powers used in these experiments. 


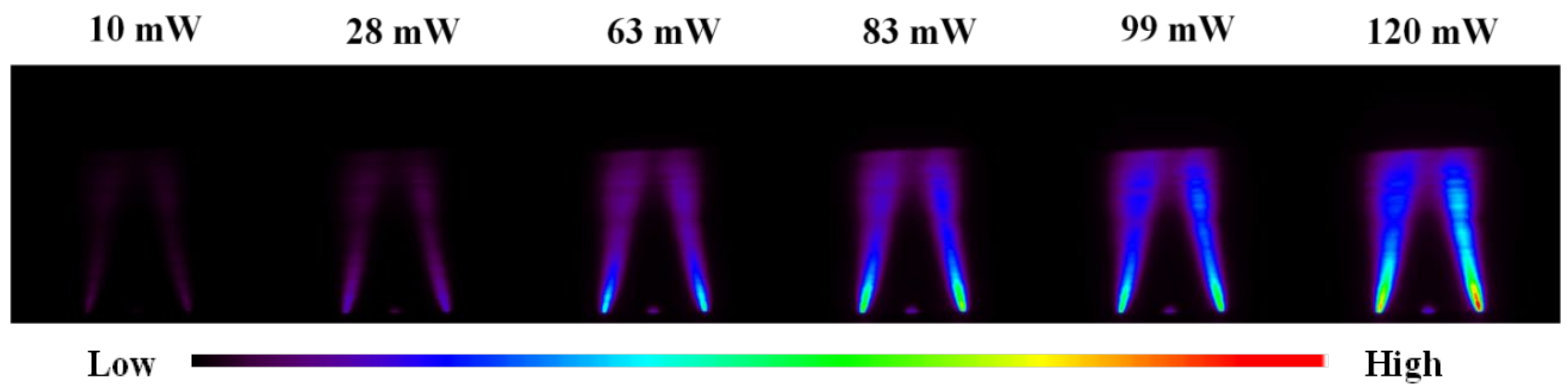

Figure 9.-Power survey for Hencken burner flame using dye/UVX laser at the $R_{2}(7)$ excitation line. Laser beam transmitted from left to right.

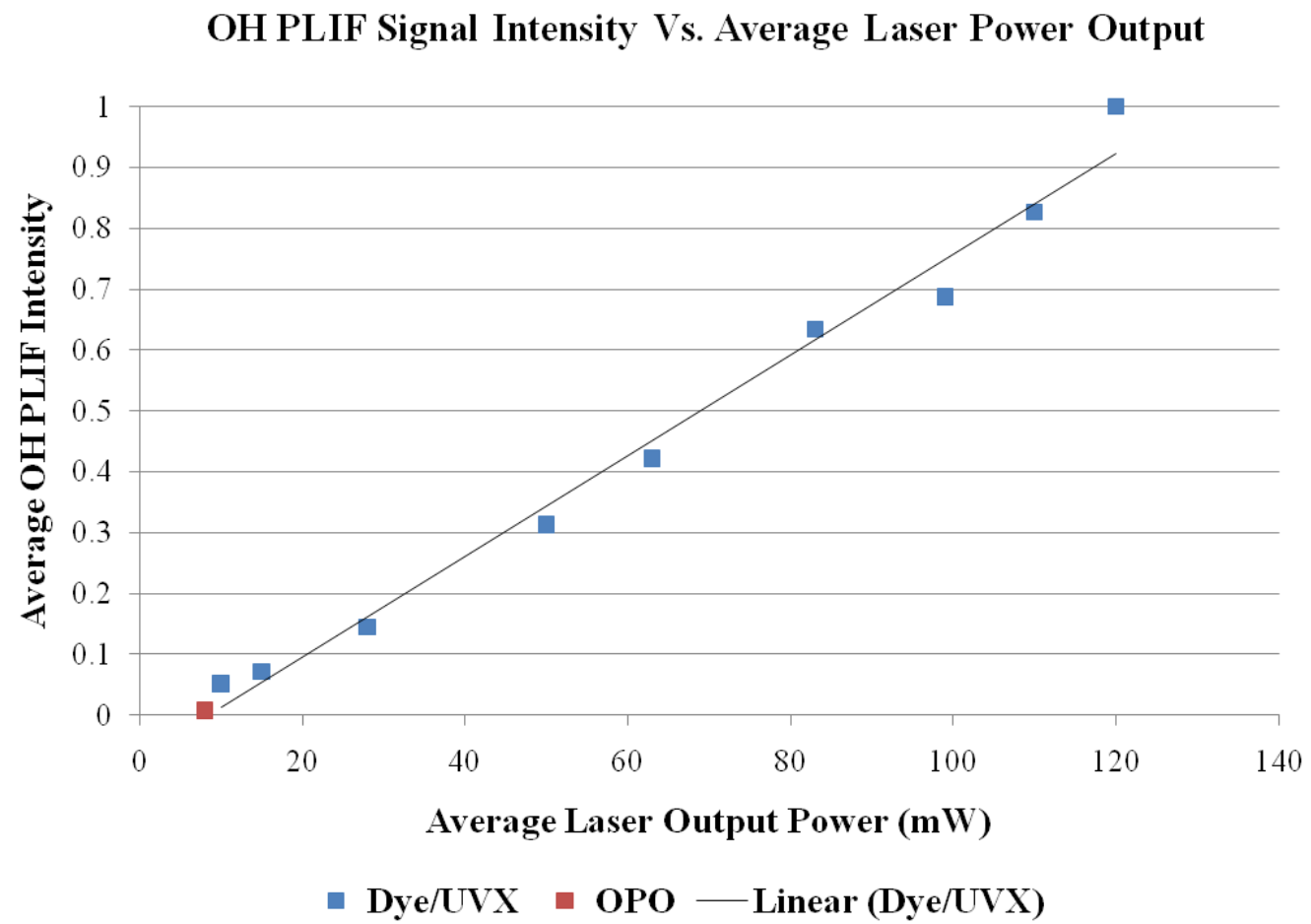

Figure 10.--Image averaged OH PLIF signal at various laser power settings demonstrating that the fluorescent signal response is within the linear regime for the full range of powers. The solid line is the linear fit to the dye/UVX laser system power survey.

\subsection{Flame Tube Combustor Experiments}

Two sets of experiments were conducted using an optically accessible flame tube combustion rig. In the first, an atmospheric pressure propane/air Bunsen burner flame was positioned in the test section of the combustor to examine the quality of the beams after expansion and transmission into the rig. The flame was operated at atmospheric pressure. The second set of data presented was obtained during testing at elevated pressure and temperature using Jet-A fuel at conditions representative of an aircraft gasturbine combustor. 


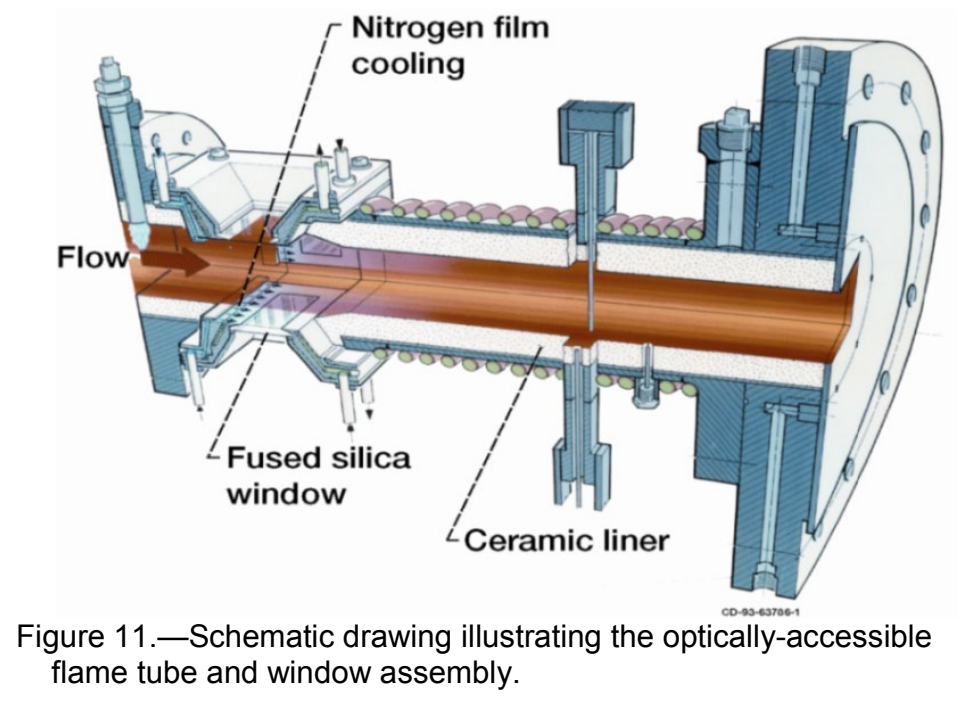

\subsection{Facility}

The flame tube used for this set of experiments is a high temperature and pressure combustion rig with partial optical access directly downstream of the fuel injection site. The optical access allows nonintrusive optical and laser-based techniques to measure chemical and physical processes during multiphase combustion. The test cell is designed to supply non-vitiated inlet air to the combustor at temperatures between 450 and $1100{ }^{\circ} \mathrm{F}(505$ to $866 \mathrm{~K}$ ) and pressures between 150 and 250 psia (1034 to $1724 \mathrm{kPa})$ with flow rates up to $10-\mathrm{lb}_{\mathrm{m}} / \mathrm{s}(4.54 \mathrm{~kg} / \mathrm{s})$. Total equivalence ratios for stable flame tube operation are generally between 0.33 and 0.55 , depending on simulated engine conditions. Because the data are acquired from a region directly downstream of the fuel injection site(s), local equivalence ratios can often be much higher, even surpassing unity. The rig is operated remotely from an adjacent control room and laser facility. (See Fig. 13). To ensure personnel safety, physical access to the facility is restricted during operation.

An isolated full-section view of the window assembly and aft flame tube are displayed in Figure 11. The combustor housing measures $0.74-\mathrm{m}$ in length and is lined with a castable ceramic to withstand average temperatures reaching $3200{ }^{\circ} \mathrm{F}(2033 \mathrm{~K})$. UV-grade fused silica windows (38.1- by $\left.50.8-\mathrm{mm}\right)$ are mounted just downstream of the fuel injection site and provide optical access to the primary reaction zone from three sides of the square combustion chamber. The chamber cross section measures 76.2- by $76.2-\mathrm{mm}$. The bottom of the chamber is typically reserved for a spark igniter and provides no optical access. The grade of fused silica used in the windows offers a minimum light transmission of 90 percent within a spectral range from 250- to 3300-nm, making it ideal for supporting optical measurements. Nitrogen film cooling is used internally to regulate window temperature and accounts for no more than 10 percent by mass of the total inlet air flow. The external housing and downstream flange section are water cooled to reduce thermal and material stresses at high temperature and pressure conditions during operation.

\subsection{Optical Setup}

Figures 12 to 14 illustrate the complete beam transport system and optical paths of the OPO and dye/UVX lasers prior to transmission into the flame tube. Both beams were initially sent through irises to isolate the primary UV light and then reflected off three mirrors before being directed vertically upward 
into a beam tube assembly, transported across the ceiling and sent back down into the flame tube combustor. The second mirror in the UVX path could be moved to project the UVX laser on the same collinear path as the OPO. The beam transport system consists of remotely-operated mirrors connected to traversing stages that permit three-dimensional PLIF data to be acquired by scanning across the flow field. The beams were allowed to expand $\sim 15-\mathrm{m}$ (by divergence) before being transformed into laser sheets. The long axis of the laser sheet was aligned with the test rig flow direction. The beams were transformed using a crossed cylindrical lens pair, one with $\mathrm{f}=3-\mathrm{m}$ to focus the sheet in the test rig (to a width of $\sim 0.3-\mathrm{mm}$ ) and the other with $\mathrm{f}=400-\mathrm{mm}$ to extend the length of the laser sheet so that it measured $\sim 3$ times the length of the window. The lens pair was used to improve the laser energy distribution across the window from the dye/UVX laser (which as shown previously, has a fairly nonuniform energy distribution). Extending the length of the laser sheet ensured use of the most uniform portion of the dye/UVX laser energy profile. Despite significant energy loss from this process, past work has indicated that using the full beam energy sometimes results in partial saturation, producing a nonlinear signal response. Although the OPO laser energy distribution was fairly uniform, its beam also passed through the cylindrical lens pair, thus losing considerable energy. Because the dye/UVX is currently the primary laser used for aircraft combustor tests, effort was made to optimize the dye laser energy distribution at the expense of the OPO.

Figure 14 is a diagram demonstrating the optical setup used for PLIF measurements in the optically accessible flame tube combustor facility. The ICCD camera used for this effort was the same one used for the methane/air burner study.

\section{ToBeam Transport}

System \& Flame Tube

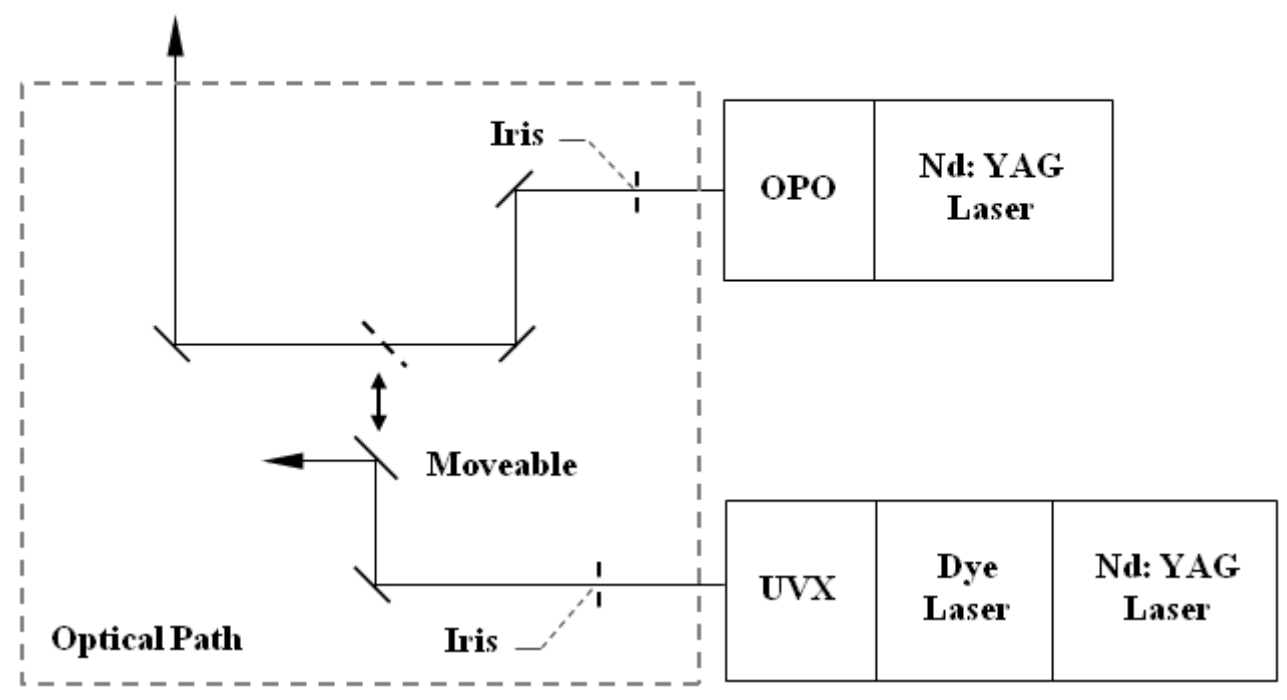

Figure 12.-Optical Path from UVX and OPO lasers to beam tubes of transport system. 


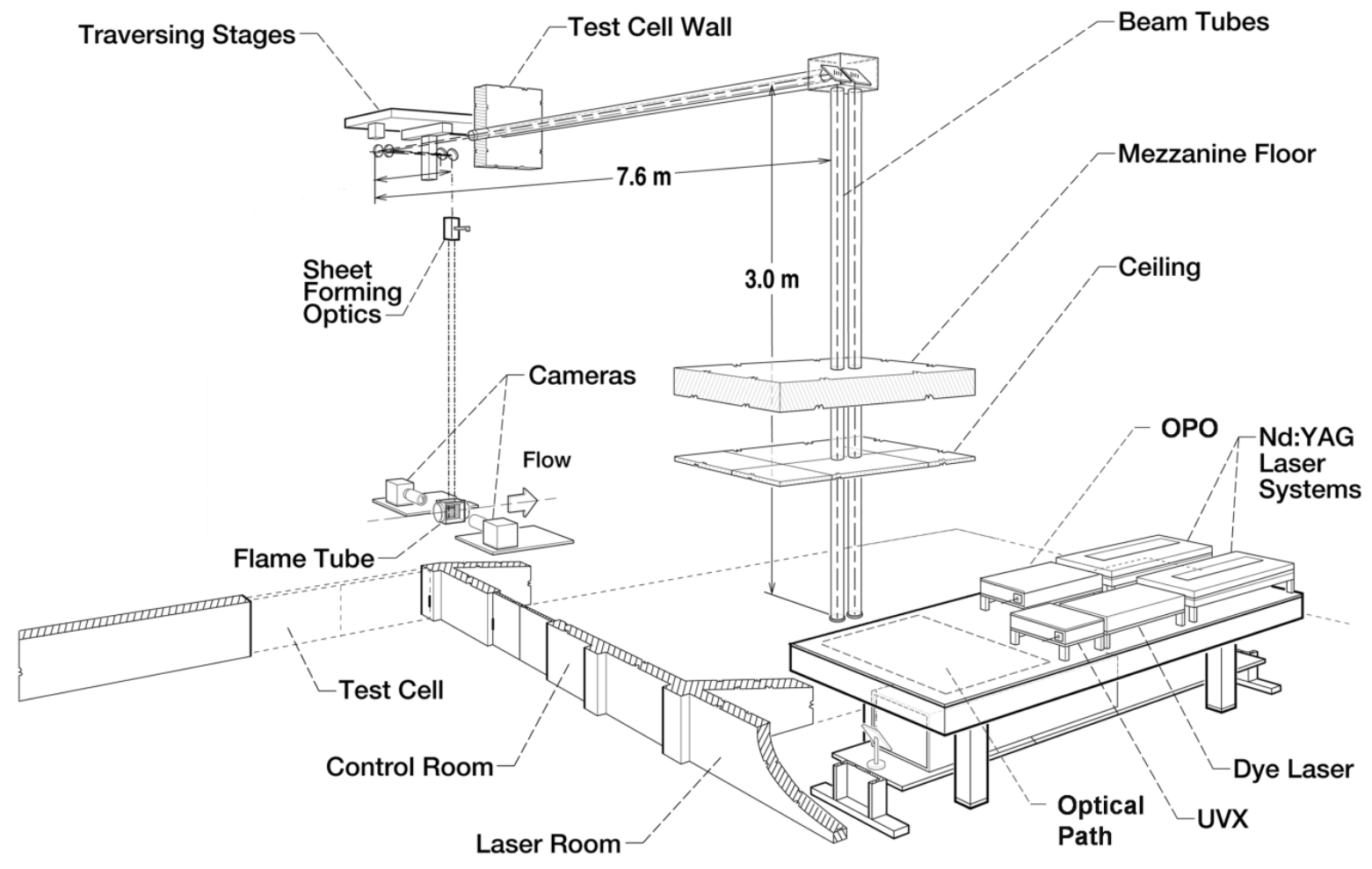

Figure 13.-Beam transport system from laser facility to flame tube combustor test cell.

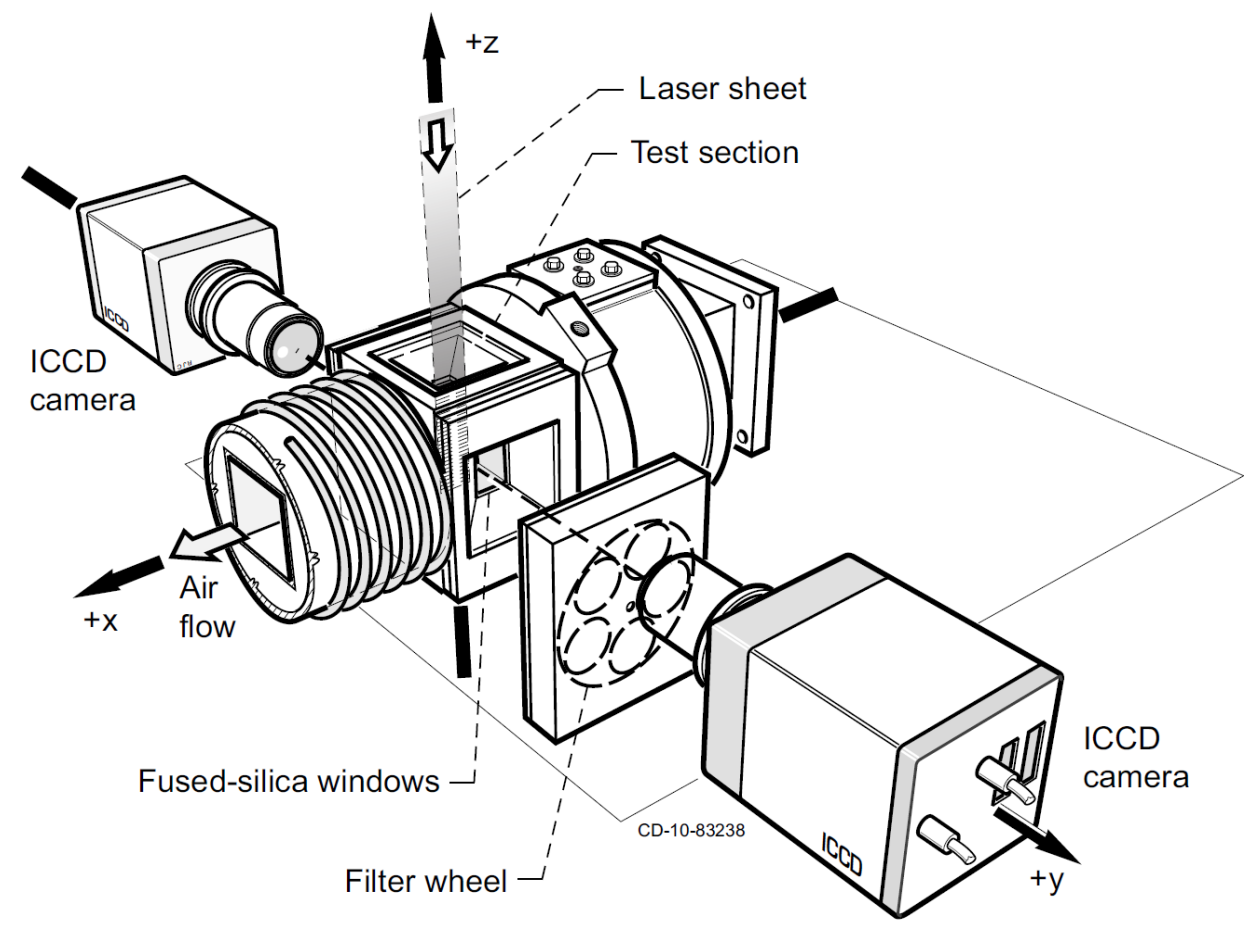

Figure 14.-Experimental PLIF setup relative to flame tube combustor rig. 

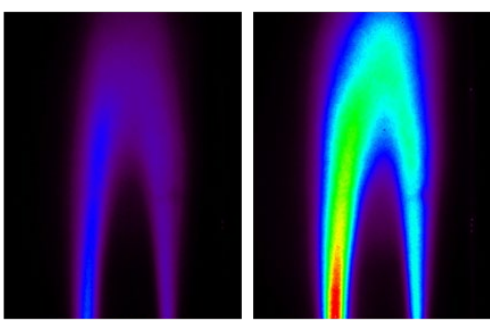

High
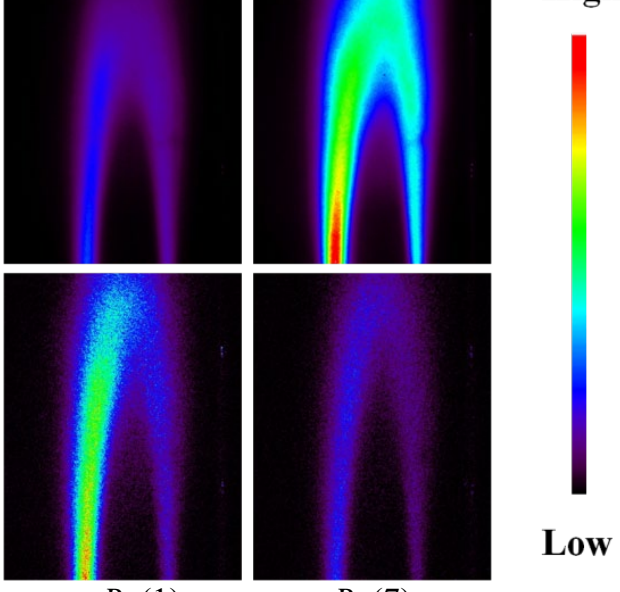

Figure 15.-OH PLIF images from propane-air flame positioned inside a flame tube combustor rig. Top row: Dye/UVX OH PLIF. Bottom row: OPO OH PLIF. Each row scaled separately. Laser beam transmitted from top to bottom.

\subsection{Bunsen Flame OH PLIF Images}

As determined from the methane-air flame experiments, the $R_{1}(10)$ excitation line was eliminated from the flame tube part of this study because of low fluorescent signal. The wide passband filter (314.4-nm, 11.8-nm FWHM) was used in all remaining tests and images were obtained by accumulating on-chip averages of 200 single shots with 50 -ns gates.

Figure 15 displays a comparison between the two laser systems using an atmospheric pressure Bunsen flame positioned inside the flame tube combustor. This preliminary test was used to compare the OH PLIF signal after the laser beams had been fully expanded and transported into the test section of the combustor rig. The propane-air burner offered a second gaseous flame with fewer complexities than the multi-component, liquid-fueled aircraft combustor flame.

The propane-air flame images duplicate the results of the methane-air flame for fluorescence intensity. Trends between the image sets are comparable to the Hencken burner data, with greater image clarity observed for the dye/UVX configuration. The OPO was able to provide only enough detail to describe the general features of this atmospheric propane/air Bunsen flame.

\subsection{Liquid-Fueled OH PLIF Flame Results}

A nine-element fuel injector was studied for the liquid-fueled PLIF imaging portion of this work. The injector is described in Reference 11 and consists of a $3 \times 3$ array measuring 76.2- by 76.2-mm with injectors spaced 25.4-mm (center-to-center) on a planar rectilinear grid. Each injector element is comprised of a set of six helical, axial vanes angled at $60^{\circ}$ surrounding a simplex nozzle that atomizes and injects liquid fuel (Jet-A) at the throat of a converging-diverging venturi. The calculated swirl number is 1.0. A single injector element is displayed in the full-section view of Figure 16. The complete array is shown in Figure 17.

PLIF was used to image $\mathrm{OH}$ and fuel at two different operating conditions inside the combustion chamber of the flame tube. Test conditions are described in Table 2 with subscript 3 denoting the inlet conditions for air upstream of the injector array. During this set of tests, only the center injector was fueled. The surrounding eight injectors were supplied with air only. All data were acquired along the vertical centerline ( $\mathrm{Y}=0$-mm plane) for the UVX and OPO laser configurations. $R_{1}(1)$ and $R_{2}(7)$ lines were tested at each operating condition. 


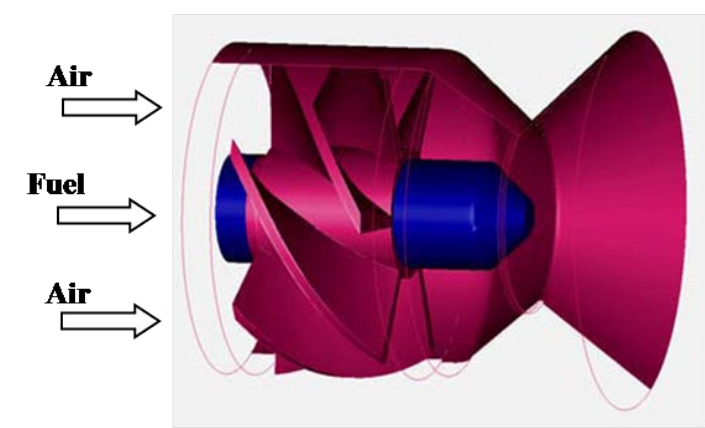

Figure 16.- Spatial positioning of the angled vanes, fuel nozzle and venturi for each injector.
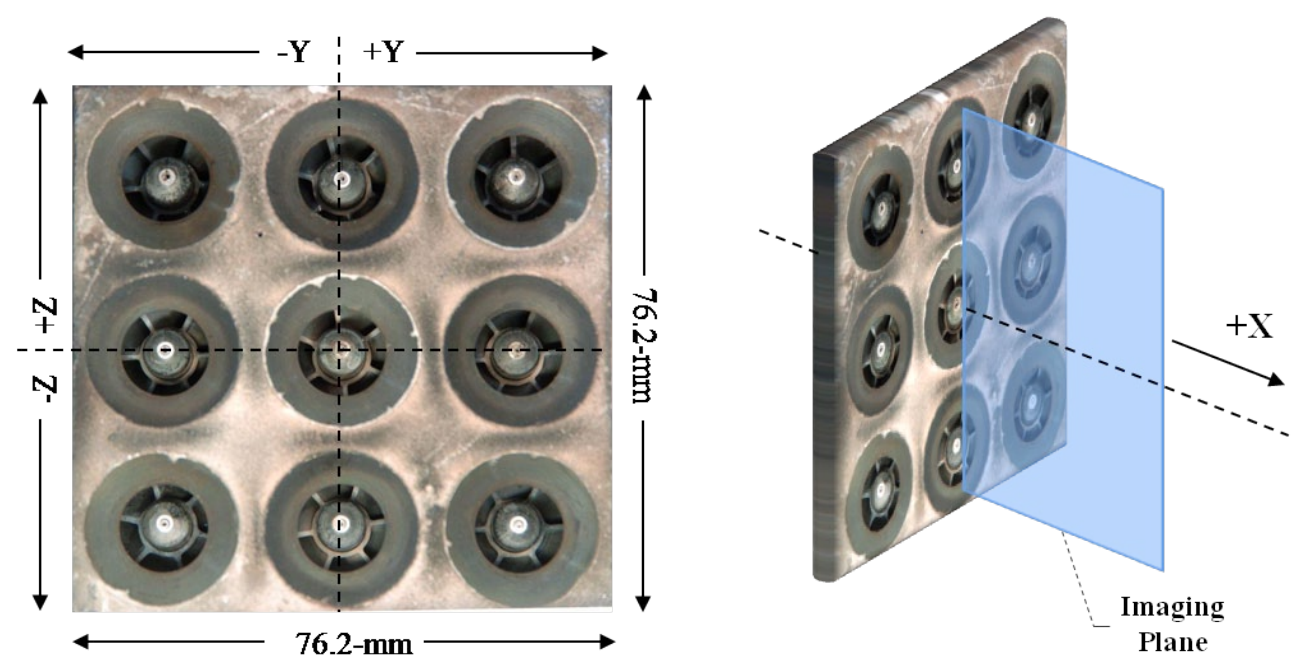

Figure 17.-End view of nine-point LDI hardware (Left). Isometric view of nine-point with imaging plane (Right).

TABLE 2.-FLAME TUBE COMBUSTOR OPERATING CONDITIONS.

\begin{tabular}{|c|c|c|c|c|c|c|}
\hline Test point & $\begin{array}{c}\mathrm{P}_{3} \\
(\mathrm{psia})\end{array}$ & $\begin{array}{c}\mathrm{T}_{3} \\
\left({ }^{\circ} \mathrm{F}\right)\end{array}$ & $\begin{array}{c}\Delta \mathrm{P} / \mathrm{P}_{3} \\
(\%)\end{array}$ & $\begin{array}{c}\mathrm{WA}_{3} \\
\left(\mathrm{lb}_{\mathrm{m}} / \mathrm{s}\right)\end{array}$ & $\Phi_{\text {center }}$ & $\Phi_{\text {total }}$ \\
\hline $\mathrm{A}$ & 150 & 1000 & 4 & 1.34 & 1.32 & 0.15 \\
$\mathrm{~B}$ & 150 & 650 & 4 & 1.53 & 1.47 & 0.16 \\
\hline
\end{tabular}

Figure 18 shows the processed PLIF images from both laser systems, with the dye/UVX results in the top row and the higher inlet temperature results (Point A) on the left. Because the fuel now contains naphthalene and its derivatives, significant fluorescent signal from fuel is present in the on-line and offline images. Subtracting the $(\mathrm{OH})$ off-line excitation images from the on-line images results in areas with comparatively low $\mathrm{OH}$ signal, shown in black. These locations are most clear in the top row images for Point B, which show a conical structure from the incoming fuel spray. There may also be regions within the fuel spray zone that have strong signal due to either fuel, $\mathrm{OH}$, or both.

Results indicate notable differences between the two operating test points and each laser. The dye/UVX system produced a much higher $\mathrm{OH}$ fluorescence signal than the OPO laser for each condition, compared to the atmospheric pressure flames, which may indicate that $\mathrm{OH}$ pressure-broadening effects are worse for the wider linewidth OPO than for the dye/UVX system. On the other hand, the lack of conical structures in the OPO images might indicate relatively low fluorescence from fuel. The $\mathrm{OH}$ signal 


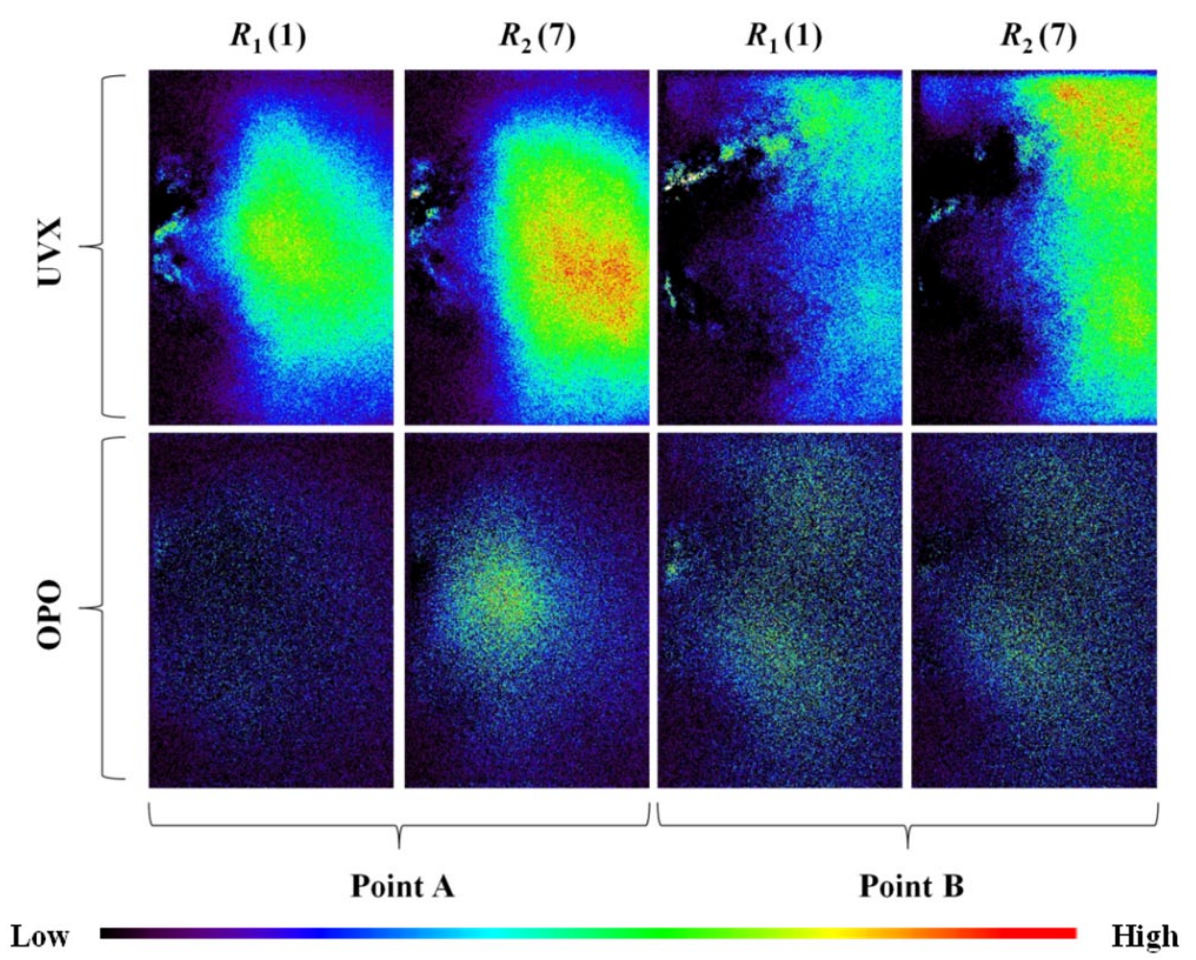

Figure 18.-PLIF images for Jet-A fueled nine-point lean direct injector array. Center injector only fueled. Each row and test point is scaled individually. Flow is from left to right.

seems to begin farther upstream in the OPO images compared to the dye/UVX images. Another feature that differs for the two laser systems is that the excitation line that provided the highest fluorescence intensity at atmospheric pressure $\left(R_{1}(1)\right)$ for the OPO changed at the higher pressure condition, but did not change for the dye/UVX system. For example, at Point $\mathrm{A}$, the OPO $R_{2}(7)$ line gives higher fluorescence signal than the $R_{1}(1)$ line and for Point $\mathrm{B}$, the fluorescence intensities are comparable; whereas for the narrow linewidth dye/UVX, the $\mathrm{OH}$ excitation results continue to show that the $R_{2}(7)$ line gives greater fluorescence signal. This result may be an indicator that $R_{2}(7)$ couples to $\mathrm{OH}$ better at higher pressure for the OPO laser. These results reinforce the need to perform more controlled experiments in a high temperature, high pressure vessel for absorption and fluorescence yields to compare the laser power, linewidth and coupling (overlap) to both $\mathrm{OH}$ and fuel molecules.

\subsection{Summary}

OH PLIF excitation/detection strategies have been tested and compared in laminar and turbulent reacting flows using a Nd:YAG pumped dye laser with UVX and a Nd:YAG pumped OPO. OH generators have included an atmospheric methane/air flame from a Hencken burner, an atmospheric propane-fueled Bunsen burner and a high temperature and high pressure Jet-A fueled lean flame tube combustor. Results indicate that the Nd:YAG pumped OPO with significantly lower power and broader linewidth is inadequate for resolving the flame structure via qualitative $\mathrm{OH}$ concentration measurements in the high pressure combustor. A low signal-to-noise ratio for the OPO along with apparent high-pressure induced effects cause a reduction in the total $\mathrm{OH}$ induced fluorescence signal. The higher energy and narrow linewidth dye/UVX combination is capable of resolving $\mathrm{OH}$ at atmospheric conditions and performs reasonably well at high pressure and temperature. In the majority of experiments from this work, the $R_{2}(7)$ line appears to induce the strongest $\mathrm{OH}$ fluorescence, followed by the $R_{1}(1)$ and $R_{1}(10)$ transition lines. The wide (11.8-nm FWHM) passband filter permitted the majority of $\mathrm{OH}$ fluorescence to pass, while still restricting much of the strong interference from 
fuel fluorescence. Absorbance calculations indicate that $R_{1}(10)$ is the least absorbing line on average in the methane/air flame experiments, followed by the $R_{2}(7)$ and $R_{1}(1)$ lines.

\subsection{Future Work}

In the next phase of this research, absorption measurements will again be performed to analyze the properties of samples of Jet-A fuel in an optically accessible high temperature, high pressure (HTHP) vessel. The vessel is designed to support sample temperatures from ambient to $800{ }^{\circ} \mathrm{C}$ at a maximum pressure of 1000-psi.

Refined OH PLIF will be performed using the same flame tube combustor rig. The OPO laser will be retrofitted with an injection seeder system that will produce a $\sim 25$ percent increase in laser energy with a $\sim 50$ percent reduction in linewidth. Results will be compared with those contained herein and improvements in performance will be noted. A beam profiler will be used so that imperfection in the laser energy distribution over the length of the laser sheet can be corrected.

The methane/air flame images, HTHP vessel and preliminary flame tube combustor results will be used to select a final excitation, extraction and correction method for acquiring advanced OH PLIF measurements. With the establishment of this optimal configuration, OH PLIF will continue to be used to characterize the operation of advanced low-emission combustion strategies in a variety of high temperature and pressure reacting environments.

\section{References}

1. Hanson, R.K., Seitzman, J.M., "Planar Laser Fluorescence Imaging of Combustion Gases," Journal of Applied Physics B, Vol. 50, No. 6, 1990, pp. 441-454.

2. Hicks, Y., Locke, R., Anderson, R., Ockunzzi, K., "Planar Imaging of Hydroxyl in a High Temperature, High Pressure Combustion Facility," NASA TM-107074, Oct. 1995.

3. Seitzman, J., Hanson, R., "Comparison of Excitation Techniques for Quantitative Fluorescence Imaging of Reacting Flows," AIAA Journal, Vol. 31, No. 3, Mar. 1993, pp. 513-519.

4. Hicks, Y., Locke, R., Anderson, R., Zaller, M., Schock, H., "Imaging Fluorescent Combustion Species in Gas Turbine Flame Tubes: On Complexities in Real Systems," NASA TM-107491, Jun. 1997; also AIAA Paper 97-2837, July 1997.

5. Dyer, M., Crosley D., "Two-Dimensional Imaging of OH Laser-Induced Fluorescence in a Flame," Optics Letters, Vol. 7, No. 8, 1982, pp. 382-384.

6. Cooper, C., Laurendeau, N., "Quantitative Laser-Saturated Fluorescence Measurements of Nitric Oxide in a Heptane Spray Flame," Journal of Combustion Science and Technology, Vol. 127, Jun. 1997, pp. 363-382.

7. Lozovsky, V., Cheskis, S., Derzy, I., Kachanov, A., Romanini, D., "Cavity Ring-Down Spectroscopy of OH Radicals in Low Pressure Flame," Journal of Applied Physics B: Lasers and Optics, Vol. 66, No. 3, 1998, pp. 377-381.

8. Baranger, P., Orain, M., Grisch, F., "Fluorescence Spectroscopy of Kerosene Vapor: Application to Gas Turbines," Proceedings of the $43^{\text {rd }}$ AIAA Aerospace Sciences Meeting and Exhibit, AIAA2005-828, Jan. 2005.

9. G.H. Dieke and H. M. Crosswhite, "The Ultraviolet Bands of OH Fundamental Data," J. Quant. Spectrosc. Radiat. Transfer, Vol. 2, pp. 97-199, 1962.

10. Allen, M., Hanson, R., "Digital Imaging of Species Concentration Fields in Spray Flames," 21 st Symposium (International) on Combustion, Combustion Inst., Pittsburgh, PA, 1987, pp. 1755-1761.

11. Tacina, R., Lee, P., Wey, C., 2005, "A Lean-Direct-Injection Combustor Using a 9 Point SwirlVenturi Fuel Injector,” ISABE 2005-1106, 2005. 


\begin{tabular}{|c|c|c|}
\hline \multicolumn{2}{|c|}{ REPORT DOCUMENTATION PAGE } & $\begin{array}{l}\text { Form Approved } \\
\text { OMB No. 0704-0188 }\end{array}$ \\
\hline \multicolumn{3}{|c|}{$\begin{array}{l}\text { The public reporting burden for this collection of information is estimated to average } 1 \text { hour per response, including the time for reviewing instructions, searching existing data sources, gathering and maintaining the } \\
\text { data needed, and completing and reviewing the collection of information. Send comments regarding this burden estimate or any other aspect of this collection of information, including suggestions for reducing this } \\
\text { burden, to Department of Defense, Washington Headquarters Services, Directorate for Information Operations and Reports ( } 0704-0188) \text {, } 1215 \text { Jefferson Davis Highway, Suite } 1224 \text {, Allington, VA } 222202-4302 \text {. } \\
\text { Respondents should be aware that notwithstanding any other provision of law, no person shall be subject to any penalty for failing to comply with a collection of information if it does not display a currently valid OMB } \\
\text { control number. } \\
\text { PLEASE DO NOT RETURN YOUR FORM TO THE ABOVE ADDRESS. }\end{array}$} \\
\hline $\begin{array}{l}\text { 1. REPORT DATE (DD-MM-YYYY) } \\
01-01-2011\end{array}$ & $\begin{array}{l}\text { 2. REPORT TYPE } \\
\text { Technical Memorandum }\end{array}$ & 3. DATES COVERED (From - To) \\
\hline \multirow{3}{*}{\multicolumn{2}{|c|}{$\begin{array}{l}\text { 4. TITLE AND SUBTITLE } \\
\text { Excitation/Detection Strategies for OH Planar Laser-Induced Fluorescence Measurem } \\
\text { the Presence of Interfering Fuel Signal and Absorption Effects }\end{array}$}} & 5a. CONTRACT NUMBER \\
\hline & & 5b. GRANT NUMBER \\
\hline & & 5c. PROGRAM ELEMENT NUMBER \\
\hline \multirow{3}{*}{\multicolumn{2}{|c|}{$\begin{array}{l}\text { 6. AUTHOR(S) } \\
\text { Heath, Christopher, M.; Anderson, Robert, C.; Hicks, Yolanda, R.; Locke, Randy, J. }\end{array}$}} & 5d. PROJECT NUMBER \\
\hline & & 5e. TASK NUMBER \\
\hline & & $\begin{array}{l}\text { 5f. WORK UNIT NUMBER } \\
\text { WBS 984754.02.07.03.19.03 }\end{array}$ \\
\hline \multicolumn{2}{|c|}{$\begin{array}{l}\text { 7. PERFORMING ORGANIZATION NAME(S) AND ADDRESS(ES) } \\
\text { National Aeronautics and Space Administration } \\
\text { John H. Glenn Research Center at Lewis Field } \\
\text { Cleveland, Ohio 44135-3191 }\end{array}$} & $\begin{array}{l}\text { 8. PERFORMING ORGANIZATION } \\
\text { REPORT NUMBER } \\
\text { E-17551 }\end{array}$ \\
\hline \multirow{2}{*}{\multicolumn{2}{|c|}{$\begin{array}{l}\text { 9. SPONSORING/MONITORING AGENCY NAME(S) AND ADDRESS(ES) } \\
\text { National Aeronautics and Space Administration } \\
\text { Washington, DC 20546-0001 }\end{array}$}} & $\begin{array}{l}\text { 10. SPONSORING/MONITOR'S } \\
\text { ACRONYM(S) } \\
\text { NASA }\end{array}$ \\
\hline & & $\begin{array}{l}\text { 11. SPONSORING/MONITORING } \\
\text { REPORT NUMBER } \\
\text { NASA/TM-2011-216947 }\end{array}$ \\
\hline \multicolumn{3}{|c|}{$\begin{array}{l}\text { 12. DISTRIBUTIONIAVAILABILITY STATEMENT } \\
\text { Unclassified-Unlimited } \\
\text { Subject Categories: } 07,34 \text {, and } 35 \\
\text { Available electronically at http://gltrs.grc.nasa.gov } \\
\text { This publication is available from the NASA Center for AeroSpace Information, 443-757-5802 }\end{array}$} \\
\hline
\end{tabular}

\section{SUPPLEMENTARY NOTES}

\section{ABSTRACT}

Planar laser-induced fluorescence (PLIF) excitation/detection methods have been applied to obtain spatial distributions of the hydroxyl [OH] reacting intermediary and hydrocarbon $[\mathrm{HC}]$ primary species in laminar and turbulent combustion reactions. In this report, broadband and narrowband excitation/filtering techniques are explored to identify an optimal experimental configuration yielding significant fluorescent signal with low absorption losses. The combustion environments analyzed include 1) a laminar non-premixed methane/air flame and 2) a turbulent, non-premixed Jet-A/air fueled flame within a lean flame tube combustor. Hydrocarbon-based fuel and $\mathrm{OH}$ were excited via the $R_{1}$ (1), $R_{1}(10)$ and $R_{2}(7)$ transitions of the $A^{2} \Sigma^{+} X^{2} \Pi(1,0)$ band using a broadband Nd:YAG pumped optical parametric oscillator (OPO) and narrowband Nd:YAG/dye laser with ultraviolet frequency extension (UVX) package. Variables tested for influence on fluorescent signal and absorption characteristics were excitation line, laser energy, exciting linewidth, combustion reactants, and test flow conditions. Results are intended to guide the transition from a dye/UVX laser to an OPO system for performing advanced diagnostics of low-emission combustion concepts.

\section{SUBJECT TERMS}

Laser diagnostics; Aircraft gas turbine combustion; Planar imaging

\begin{tabular}{|c|c|c|c|c|}
\hline \multicolumn{3}{|c|}{ 16. SECURITY CLASSIFICATION OF: } & \multirow{2}{*}{$\begin{array}{l}\text { 17. LIMITATION OF } \\
\text { ABSTRACT } \\
\text { UU }\end{array}$} & \multirow{2}{*}{$\begin{array}{l}\text { 18. NUMBER } \\
\text { OF } \\
\text { PAGES } \\
25\end{array}$} \\
\hline $\begin{array}{l}\text { a. REPORT } \\
U\end{array}$ & $\begin{array}{l}\text { b. ABSTRACT } \\
U\end{array}$ & $\begin{array}{l}\text { c. THIS } \\
\text { PAGE } \\
U\end{array}$ & & \\
\hline
\end{tabular}



